\title{
Safety and Efficacy of Aneurysm Treatment with the WEB: Results of the WEBCAST 2 Study
}

\author{
(D). Pierot, (DI. Gubucz, (D).H. Buhk, (D) M. Holtmannspötter, (DD. Herbreteau, (DL. Stockx, (D). Spelle, (D). Berkefeld, (D)A.-C. Januel, \\ (D) A. Molyneux, (D).V. Byrne, (D). Fiehler, (D). Szikora, and (D)X. Barreau
}

\begin{abstract}
BACKGROUND AND PURPOSE: Flow disruption with the Woven EndoBridge (WEB) device is an innovative technique for the endovascular treatment of wide-neck bifurcation aneurysms. The initial version of the device (WEB Double-Layer) was evaluated in the WEB Clinical Assessment of IntraSaccular Aneurysm Therapy (WEBCAST) study, whereas the French Observatory study evaluated both WEB Double-Layer and Single-Layer versions of the device. WEBCAST 2 was designed to evaluate the WEB Single-Layer with Enhanced Visualization.
\end{abstract}

MATERIALS AND METHODS: Patients with wide-neck bifurcation aneurysms for which WEB treatment was possible were included. Clinical data including adverse events and clinical status at 1 month and 1 year were collected and analyzed. A core laboratory evaluated anatomic results at 1 year following the procedure.

RESULTS: Ten European neurointerventional centers included 55 patients ( 38 women; $27-77$ years of age; mean, $54.4 \pm 10.0$ years) with 55 aneurysms. Aneurysm locations were the middle cerebral artery in 25 aneurysms (45.5\%), the anterior communicating artery in 16 (29.1\%), the basilar artery in 9 (16.4\%), and the internal carotid artery terminus in 5 (9.1\%). Procedural morbidity and mortality at 1 month were, respectively, $1.8 \%$ (1/55 patients) and $0.0 \%$ (0/55 patients). Morbidity and mortality at 1 year were, respectively, $3.9 \%$ ( $2 / 51$ patients) and $2.0 \%$ (1/51 patients). At 1 year, complete occlusion was observed in 27/50 aneurysms (54.0\%); neck remnant, in 13/50 (26.0\%); and aneurysm remnant, in 10/50 (20.0\%) (adequate occlusion in 40/50, 80.0\%).

CONCLUSIONS: WEBCAST 2 confirms the high safety and efficacy of WEB aneurysm treatment demonstrated in the WEBCAST and French Observatory studies.

ABBREVIATIONS: EV = Enhanced Visualization; WEB = Woven EndoBridge; WEBCAST = WEB Clinical Assessment of IntraSaccular Aneurysm Therapy; WEB-DL = WEB Double-Layer; WEB-SL = WEB Single-Layer; WEB-SLS = Single-Layer Spherical

E ndovascular treatment is now the first-line treatment for ruptured aneurysms. ${ }^{1}$ For unruptured aneurysms, no randomized trial has been completed that permits the direct comparison of clipping with endovascular treatment. However, at least in Europe, the tendency is to give priority to endovascular treatment. ${ }^{2}$

Received November 15, 2016; accepted after revision February 7, 2017

From the Department of Neuroradiology (L.P.), Hôpital Maison-Blanche, Université Reims-Champagne-Ardenne, Reims, France; National Institute of Clinical Neurosciences (I.G., I.S.), Budapest, Hungary; Department of Neuroradiology (J.H.B., J.F.), University Medical Center Hamburg-Eppendorf, Hamburg, Germany; Rigshospitalet (M.H.), Copenhagen, Denmark; Centre Hospitalier Universitaire Tours (D.H.), Tours, France; Ziekenhuis Oost-Limburg Genk (L. Stockx), Genk, Belgium; Hôpital Bicêtre (L. Spelle), Assistance Publique-Hôpitaux de Paris, Le Kremlin Bicêtre, France; Institut für Neuroradiologie (J.B.), Klinikum der Johann Wolfgang Goethe-Universitaet, Frankfurt, Germany; Centre Hospitalier Universitaire Toulouse (A.-C.J.), Toulouse, France; Oxford Neurovascular and Neuroradiology Research Unit (J.V.B., A.M.), John Radcliffe Hospital, Oxford, UK; and Centre Hospitalier Universitaire Bordeaux (X.B.), Bordeaux, France.

The WEBCAST 2 trial was supported by Sequent Medical.

Clinical Trial Registration is provided at http://www.clinicaltrials.gov. The unique identifier is NCT01778322.
Some aneurysms, especially those with a wide-neck, are difficult to treat due to the challenges of stabilizing coils inside the aneurysm sac and avoiding their protrusion into the parent artery. Thus, more complex endovascular techniques have been developed, such as balloon-assisted coiling, stent-assisted coiling, and flow diversion. ${ }^{3-8}$

Flow disruption is now a well-established procedure for the treatment of wide-neck bifurcation aneurysms. ${ }^{9-13}$ Today, it is also used in narrow-neck aneurysms and sidewall aneurysms. ${ }^{14}$ The therapy involves the placement of an intrasaccular device that alters the flow inside the aneurysm, inducing intrasaccular thrombosis. Introduced in 2010 in Europe, the Woven EndoBridge (WEB; Sequent Medical, Aliso Viejo, California) is the only intrasaccular device that has been extensively evaluated in

Please address correspondence to Laurent Pierot, MD, PhD, Department of Neuroradiology, Hôpital Maison-Blanche, 45 Rue Cognacq-Jay, 51092 Reims Cedex, France; e-mail: Ipierot@gmail.com

http://dx.doi.org/10.3174/ajnr.A5178 
the literature with several single- and multicenter, retrospective, and prospective series. ${ }^{9-21}$ Good Clinical Practice studies, including the WEB Clinical Assessment of IntraSaccular Aneurysm Therapy (WEBCAST) and the French Observatory studies, have shown a high level of safety with the device. ${ }^{15-18}$ Efficacy has to be further evaluated, but 1-year anatomic results in both the WEBCAST and French Observatory studies are encouraging. However, important changes in the device have been introduced across the time, moving from a dual-layer, larger profile version (WEB-DL) to single-layer, lower profile versions (WEB-SL and WEB SingleLayer Spherical [SLS]) and more recently Single-Layer with Enhanced Visualization (EV) obtained by introducing composite wires of nitinol and platinum in the braid itself.

The WEBCAST study evaluated the WEB-DL, whereas the French Observatory evaluated the WEB-DL, WEB-SL, and the WEB-SLS. ${ }^{15-18}$ In the continuing effort to assess the clinical and anatomic performance of these new devices, it was logical to further evaluate this technique with a series of patients treated exclusively with single-layer (SL, SLS) and Enhanced Visualization devices.

\section{MATERIALS AND METHODS}

WEBCAST 2 is a prospective, consecutive, multicenter, European registry dedicated to the evaluation of WEB-SL EV and WEB-SLS EV treatment for bifurcation aneurysms.

The study received national regulatory authorization (Advisory Committee on Information Processing in Material Research in the Field of Health), Reims Institutional Review Board approval, and National Commission for Data Processing and Freedom approval. Written informed consent was obtained for all patients.

\section{Trial Design and Procedural Modalities}

WEBCAST 2 protocol was similar to that in WEBCAST with some amendments. ${ }^{17}$ Inclusion criteria were ruptured (Hunt and Hess 1,2 , or 3 ) and unruptured bifurcation aneurysms located in the basilar artery, middle cerebral artery, anterior communicating artery, posterior communicating artery, and internal carotid artery terminus. The indication for endovascular treatment was determined in each center by a local multidisciplinary team that included neurosurgeons and neuroradiologists. The selection of aneurysms treated with the WEB device was performed autonomously in each center by the interventional neuroradiologists according to aneurysm characteristics (aneurysm status, aneurysm location and size, and neck size).

The treatment of aneurysms with the WEB was performed by using techniques similar to those used in the treatment of aneurysms with coils. The study protocol did not specify the antiplatelet regimen to be followed, and it was managed in each center as indicated for typical endovascular treatment with coils or stents and coils. Triaxial access was recommended. A very careful sizing of the aneurysm was recommended because previous evaluation showed that oversizing of the device plays an important role in the quality of anatomic results. On the basis of the size of the WEB device to be used, VIA-21 (WEB SL/SLS 4-7 mm), VIA-27 (WEB SL/SLS 8-9 mm), and VIA-33 (WEB SL/SLS $1011 \mathrm{~mm}$ ) microcatheters (Sequent Medical) were used to catheterize the aneu- rysm. If the treatment plan included use of ancillary implant devices, the patient was not enrolled in the study. Treatment with ancillary devices (coils, stent, flow diverters) was allowed during the procedure if deemed necessary by the physician and was not considered a treatment failure.

\section{Data Collection}

The following data were collected for each patient: age and sex; aneurysm rupture status; aneurysm characteristics including location, size, and neck size; date of the procedure; perioperative antiplatelet medications; occurrence of complications during or after the procedure; and use of additional devices during the procedure (coils, remodeling balloons, stents, or flow diverters). The preoperative Hunt and Hess grade was collected in case of ruptured aneurysms. The modified Rankin Scale score was collected before treatment (unruptured aneurysms) and at $30 \pm 7$ days and $12 \pm 3$ months for all patients. Vascular imaging at $12 \pm 3$ months was collected.

\section{Data Analysis}

Clinical data were independently monitored and analyzed, including all adverse events. Morbidity was defined as mRS $>2$ if preoperative $\mathrm{mRS}$ was $\leq 2$ (or in case of ruptured aneurysm), or an increase of 1 point when the preoperative mRS was $>2$.

An expert interventional neuroradiologist (J.B.) independently evaluated aneurysm measurements and occlusion by using a 3-grade scale: complete occlusion, neck remnant, and aneurysm remnant. According to a previous publication, opacification of the proximal recess of the WEB device was considered complete occlusion. $^{15}$

\section{Statistical Analysis}

Continuous variables were described as mean \pm SD. Categoric data were described numerically as a categoric total and as a percentage of the population analyzed. Binomial data were described as a ratio of the true value and the population analyzed. Confidence intervals for binomial data were calculated by the ClopperPearson method, and $P$ values were calculated by the Fisher exact test. Analyses were conducted by using SPSS statistical software (IBM, Armonk, New York) for confidence intervals and $P$ values.

\section{RESULTS}

\section{Patient and Aneurysm Population}

Between August 2014 and May 2015, 10 European centers included 55 patients (38 women, 69.1\%; 27-77 years of age; mean, $54.4 \pm 10.0$ years) with 55 aneurysms.

Four (7.3\%) aneurysms were ruptured, and 51 (92.7\%), unruptured. In patients with ruptured aneurysms, the Hunt and Hess grade was 1 in 1 patient and 3 in 3 patients. For patients treated for unruptured aneurysms, the preoperative mRS was 0 in $39 / 51$ patients $(76.5 \%), 1$ in $10 / 51$ patients $(19.6 \%), 2$ in $1 / 51$ patients $(2.0 \%)$, and 4 in $1 / 51$ patients $(2.0 \%)$. Aneurysm locations were the MCA in 25 aneurysms (45.5\%), the anterior communicating artery in $16(29.1 \%)$, the basilar artery in $9(16.4 \%)$, and the ICA terminus in $5(9.1 \%)$. The aneurysm neck was between 2.5 and $8.0 \mathrm{~mm}$ (mean, $4.6 \pm 1.1 \mathrm{~mm}$ ). The aneurysm neck was $\geq 4 \mathrm{~mm}$ in $41 / 55$ aneurysms $(74.5 \%)$. Aneurysm size was 
between 2.8 and $17.0 \mathrm{~mm}$ (mean, $6.7 \pm 2.3 \mathrm{~mm}$ ). The aneurysm was $\geq 10 \mathrm{~mm}$ in $3 / 55$ aneurysms $(5.5 \%)$.

Modalities of antiplatelet treatment before, during, and after the procedure are described in Table 1.

\section{Treatment Feasibility, Adjunctive Treatments, and Adverse Events}

Treatment was successfully performed in all except 2 patients (96.4\%), with the WEB-SL in 47/53 patients and the WEB-SLS in $6 / 53$ patients.

An adjunctive device (flow diverter and stent) was used in 1/53 aneurysms (1.9\%).

Intraoperative thromboembolic events were reported in 8 patients $(8 / 55,14.5 \%)$. Four of these 8 patients had 1 antiplatelet agent, and 4 had 2 antiplatelet agents before the complication. There was no clinical worsening in 2 patients (3.6\%), a transient deficit in 3 patients $(5.4 \%)$, and a permanent deficit in 3 patients (5.4\%). These 3 patients had a 1-month mRS of, respectively, 1, 2, and 3.

Another thromboembolic event was reported 5 months postprocedure, related to a concurrent condition (history of stroke). The patient had dual antiplatelet treatment before and after the procedure. The patient had a small cerebral infarct, which was not associated with a permanent deficit.

Intraoperative rupture was reported in $1 / 55$ patients $(1.8 \%)$ and was not symptomatic.

\section{Mortality/Morbidity at 1 Month}

At 30 days, all patients enrolled in the study had a clinical evaluation with mRS scoring. There was no mortality at 1 month. Procedural morbidity was observed in $1 / 55$ patients (1.8\%) related to a thromboembolic event ( $\mathrm{mRS} 3$ ). One patient (1.8\%) with a ruptured aneurysm was mRS 4 at 1 month due to the initial bleeding. Global morbidity at 1 month was 3.6\% (2/55).

\section{Mortality/Morbidity at 1 Year}

At 12 months, 51 of the 55 patients enrolled in the study were clinically evaluated with mRS scoring. Four patients were not included in the 1 year mortality/morbidity analysis (2 patients not treated with the WEB, 1 patient lost for follow-up, and 1 patient withdrawing his consent before 12-month follow-up).

One patient died between 1 month and 1 year follow-up: This patient had a huge retroperitoneal hematoma after the WEB procedure, further associated with intensive care complications (cardiac and respiratory). Mortality at 1 year was $1 / 51$ (2.0\%). Among the 2 patients who had mRS $>2$ at 1 month, the patient with the initial ruptured aneurysm improved at 1 year (mRS 2 ). The patient with a TE event due to the procedure was still mRS 3 at 1 year. Another patient retreated at 14 months with a flow diverter had a thromboembolic complication with mRS 3 at discharge. Global morbidity at 1 year was $2 / 51(3.9 \%)$.

\section{Retreatment}

Of the 53 aneurysms treated with the WEB, aneurysm occlusion and retreatment were not evaluated in 3 patients at 1 year: One patient died, 1 patient withdrew consent, and follow-up was missing for 1 patient. During the $12 \pm 3$ months' follow-up period, $4 / 50$ aneurysms $(8.0 \%)$ were retreated or had an attempted retreatment (Table 2). In all 4 cases, aneurysm remnants were detected at 6 months. In 1 patient, additional treatment by clipping was attempted 8 months after the initial procedure. Clipping was unsuccessful, and the patient had hemiplegia immediately after the procedure. Neurologic improvement was rapid, and the patient was mRS 2 at 1 year. This aneurysm was successfully retreated with the WEB SLS at 14 months. In another case, retreatment with Y-stent placement and coiling took place 10 months after the initial treatment.

In the 2 other cases, aneurysm retreatment took place after the 1 -year DSA showed that the aneurysm remnant remained. Retreatment was performed in these 2 patients at 14 months. One was successfully retreated with Y-stent placement and coiling, and 1 patient was treated with a flow diverter. For this last patient, an intrastent thrombosis occurred during the procedure and the flow diverter was removed. The patient had clinical worsening with mRS 3 at discharge.

\section{Anatomic Results at 1 Year}

The vascular imaging technique was digital subtraction angiography in $39 / 50$ patients $(78.0 \%)$, MRA in 10 patients $(20.0 \%)$, and CTA in 1 patient $(2.0 \%)$.

Complete occlusion was observed in 27/50 aneurysms (54.0\%); neck remnant, in 13/50 aneurysms (26.0\%); and aneurysm remnant, in $10 / 50$ aneurysms $(20.0 \%)$. Adequate occlusion (complete occlusion or neck remnant) was observed in 40/50 aneurysms (80.0\%).
Table 1: Antiplatelet treatment before, during, and after WEB procedure

\begin{tabular}{lccc}
\hline & Before & During & After (1-Mo FU) \\
\hline No antiplatelet (No.) & $16 / 55(29.1 \%)$ & $10 / 55(18.2 \%)$ & $11 / 55(20.0 \%)$ \\
Single antiplatelet (No.) & $15 / 55(27.3 \%)$ & $16 / 55(29.1 \%)$ & $31 / 55(56.4 \%)$ \\
Dual antiplatelet (No.) & $24 / 55(43.6 \%)$ & $29 / 55(51.7 \%)$ & $13 / 55(23.6 \%)$ \\
\hline
\end{tabular}

Note:-FU indicates follow-up.

\section{DISCUSSION}

The rapid technologic evolution of the WEB device (Single-Layer, Enhanced Visualization) makes it necessary to have a proper evaluation of the latest generation of devices. In continuity with previ-

Table 2: Retreatment completed $12 \pm 3$ months

\begin{tabular}{lccccc}
\hline $\begin{array}{c}\text { Patient Sex, } \\
\text { Age (yr) }\end{array}$ & $\begin{array}{c}\text { Aneurysm } \\
\text { Location }\end{array}$ & $\begin{array}{c}\text { Aneurysm Transverse } \\
\text { Diameter }(\mathbf{m m})\end{array}$ & $\begin{array}{c}\text { WEB } \\
\text { Size (mm) }\end{array}$ & $\begin{array}{c}\text { Retreatment } \\
\text { Delay (mo) }\end{array}$ & Retreatment Type \\
\hline M, 65 & AcomA & 6.3 & SL 6 63 & 14 & Y-stenting/coils \\
F, 41 & MCA & 5.9 & SL $6 \times 3$ & 8,14 & Operation (failed)/WEB SLS \\
F, 27 & BA & 7.9 & SL 10 $\times 5$ & 10 & Y-stenting/coils \\
F, 50 & BA & $9.6^{\mathrm{a}}$ & SLS 11 & 14 & Flow diverter (failed) \\
\hline
\end{tabular}

Note:-AcomA indicates anterior communicating artery; BA, basilar artery.

${ }^{a}$ Giant partially thrombosed aneurysm. Transverse diameter of the circulating part. 
ously published WEB Good Clinical Practice studies (WEBCAST, French Observatory) and in parallel with ongoing Good Clinical Practice studies (WEB- Intrasaccular Therapy Study under FDA investigational device exemption in the United States, and CLinical Assessment of WEB Device in Ruptured aneurYSms [CLARITY] in Europe), WEBCAST 2 was designed according to the same protocol as WEBCAST to evaluate the WEB-SL with Enhanced Visualization in wide-neck bifurcation aneurysms. ${ }^{17}$ However, recent reports have outlined the possibility of using the WEB in other indications, including sidewall and narrow-neck aneurysms not included in WEBCAST $2 .^{14}$

The results of WEBCAST 2 confirm that WEB treatment, with lower profile devices and smaller inner diameter microcatheters, is highly feasible, with a technical success rate of $96.4 \%$, similar to that observed in the WEBCAST (94.1\%) and the French Observatory (98.4\%) studies. $^{16,17}$ All patients in WEBCAST were treated with the WEB-DL, and in the French Observatory, 31/63 aneurysms were treated with the WEB-DL, with the remaining aneurysms treated with the WEB-SL or -SLS (most without the EV materials). Of note, the feasibility rate is not higher in WEBCAST 2 than in WEBCAST, given that the WEB-SL and SLS were thought to be easier to navigate and deploy. In fact, the selection of patients and aneurysms for WEB treatment was different in WEBCAST and WEBCAST 2 as illustrated by the higher percentage of anterior communicating artery aneurysms treated in WEBCAST 2 (29.1\%) compared with WEBCAST (7.8\%). A similar difference in patient/aneurysm selection when treating with the WEB-DL and WEB-SL and SLS was also observed in the French Observatory study. ${ }^{15,16}$

WEBCAST 2 confirms the high safety of aneurysm treatment with the WEB observed in the WEBCAST study. Morbidity and mortality at 1 month were very similar at $2.0 \%$ and $0.0 \%$, respectively. ${ }^{17}$ Similar results were also reported in the French Observatory with 1 -month morbidity at $3.2 \%$ and mortality at $0.0 \% .^{15,16}$ Moreover, morbidity and mortality at 1 month were not different in the DL and SL/SLS groups.

Efficacy as evaluated with anatomic results at 1-year is as good in WEBCAST 2 as in the WEBCAST (at 6 months) and French Observatory studies. Adequate occlusion was observed in $80.0 \%$ in WEBCAST 2, 85.4\% in WEBCAST, and 79.3\% in French Observatory. ${ }^{16,17}$ This result is quite important because it means that the new braiding of the single-layer devices provides a low-porosity equivalent, at least in term of anatomic results, to the previous braiding placed in 2 layers at the level of the neck. The new braiding decreases the porosity and provides a single-layer device that is less rigid than a dual-layer one, and easier to navigate, without worsening its efficacy. Also, the single-layer device has permitted a reduction in the size of the microcatheter used for delivery and deployment.

Finally, the retreatment rate is similar to that reported in the cumulative population of the WEBCAST and French Observatory studies, in which the retreatment rate was $6.4 \%$, including retreatment effectively performed $(3.6 \%)$, failed retreatment $(0.9 \%)$, and planned retreatment $(1.8 \%)$. In WEBCAST 2, retreatment was performed in 2 patients when the WEB device was not oversized (as currently recommended) and in 1 patient with a giant partially thrombosed aneurysm. A recent, single-center series showed that adequate occlusion was more frequent (but not significantly so) when the WEB device was appropriately sized (92.9\%) than undersized (70.0\%). ${ }^{22}$ In WEBCAST 2, two patients were retreated as a consequence of WEB undersizing; this scenario must be avoided.

Compared with alternative therapeutics, the safety of aneurysms treatment with the WEB-SL is similar to that of coiling. In CLARITY (ruptured aneurysms) and Analysis of Treatment by Endovascular Approach of Nonruptured Aneurysms (ATENA) (unruptured aneurysms), intraoperative rupture occurred in $3.7 \%$ and $2.6 \%$, respectively, and thromboembolic events, in $13.3 \%$ and $7.1 \%$, respectively. ${ }^{1,2}$ In ATENA, morbidity and mortality rates at 1 month were $1.7 \%$ and $1.4 \%$, respectively, whereas in CLARITY, treatment morbidity and mortality were $3.7 \%$ and $1.5 \%$, respectively. Comparison with surgical series is more difficult because the rate of thromboembolic events and intraoperative rupture is rarely reported, possibly because it is less frequent or underestimated. ${ }^{23}$ When we looked at the morbidity/mortality, in the largest meta-analysis dealing with unruptured aneurysms treated by clipping, the rate of death $(1.7 \%)$ was higher compared with that in WEBCAST $2(0.0 \%)$ and the rate of unfavorable outcome at 1 year was $6.7 \%$ compared with $5.9 \%$ in WEBCAST $2 .^{23}$ The same meta-analysis showed interesting results regarding the efficacy of clipping. In $82.2 \%$ of all clipped aneurysms, the postoperative aneurysm occlusion rate was not reported. When it was reported, it was not independently evaluated (unlike the entire series of Good Clinical Practice WEB studies). When reported, complete occlusion was $91.8 \%$ (neck remnant in $3.9 \%$ and aneurysm remnant in $4.3 \%$ ). There are no data on longterm follow-up.

This study has several limitations. First, the population was relatively small (55 patients). However, it is the first prospective, multicenter study evaluating the safety and efficacy of aneurysm treatment with WEB-SL and WEB-SLS devices with independent assessment of adverse events and anatomic results. Second, it is not a randomized study, and comparison with other techniques is not easy. However, safety data are excellent and quite comparable with those observed in large coiling series. Efficacy data are more difficult to compare with historical series because most are mixed sidewall and bifurcation locations, with both narrow- and wideneck aneurysms. Third, the potential WEB "compression” phenomenon has not been evaluated in this study, and further work is being conducted on this topic. ${ }^{24,25}$ Finally, anatomic results were evaluated with heterogeneous imaging techniques (DSA, MRA, and CTA), and MRA has a relatively low sensitivity for aneurysm remnant detection. ${ }^{26}$

\section{CONCLUSIONS}

WEBCAST 2 results are in line with WEBCAST and French Observatory results, showing high safety and great efficacy of aneurysm treatment with WEB-SL devices.

Disclosures: Laurent Pierot-RELATED: Consulting Fee or Honorarium: Sequent Medical; UNRELATED: Consultancy: Blockade Medical, Medtronic, MicroVention, Neuravi, Penumbra. Jan Hendrik Buhk_UNRELATED: Consultancy: Acandis, Codman Neurovascular, MicroVention, Sequent Medical. Markus Holtmannspötter-UNRELATED: Consultancy: MicroVention, Covidien, Sequent Medical, Mentice, Stryker, Comments: consultancy and proctoring fees; Payment for Lectures Including Service on Speakers Bureaus: MicroVention, Covidien, Sequent Medical; Travel/Ac- 
commodations/Meeting Expenses Unrelated to Activities Listed: MicroVention, Covidien, Sequent Medical, Mentice, Stryker. Denis Herbreteau-RELATED: Support for Travel to Meetings for the Study or Other Purposes: Sequent Medical; Other: Sequent, Comments: proctoring; UNRELATED: Payment for Manuscript Preparation: Sequent Medical; Travel/Accommodations/Meeting Expenses Unrelated to Activities Listed: Sequent Medical. Laurent Spelle-UNRELATED: Consultancy: Sequent, Medtronic, Stryker. Joachim Berkefeld_RELATED: Consulting Fee or Honorarium: Sequent Medical; Support for Travel to Meetings for the Study or Other Purposes: Sequent Medical, Comments: invited speaker for user meetings and sponsored symposium; UNRELATED: Board Membership: Acandis, Pforzheim, Germany, Comments: member of the scientific advisory board; Consultancy: Siemens, Erlangen, Germany, Comments: scientific cooperation.* Anne-Christine Januel—UNRELATED: Grant: Association pour le développement de la Neuroradiologie, Comments: for data monitoring*; Travel/Accommodations/Meeting Expenses Unrelated to Activities Listed: Sequent, Comments: fees and accommodation paid for participation in meetings. Andrew Molyneux-RELATED: Grant: Sequent; Consulting Fee or Honorarium: Sequent Medical, Comments: time for consulting to review adverse events*; Fees for Participation in Review Activities such as DataMonitoring Boards, Statistical Analysis, Endpoint Committees, and the Like: attended the Society of Neurolnterventional Surgery investigator meeting. James $\mathrm{V}$. Byrne-UNRELATED: Employment: Oxford University Hospital National Health Service Trust, Comments: salary as consultant interventional neuroradiologist; Fees for Participation in Review Activities such as Data-Monitoring Boards, Statistical Analysis, Endpoint Committees, and the Like: Nuffield Department of Surgical Sciences, Oxford University, Comments: contracted core laboratory services. * Jens FiehlerRELATED: Consulting Fee or Honorarium: Sequent Medical; Support for Travel to Meetings for the Study or Other Purposes: Sequent Medical; UNRELATED: Consultancy: MicroVention, Covidien, Stryker, Codman, Medina, Penumbra; Payment for Lectures Including Service on Speakers Bureaus: MicroVention, Covidien, Stryker, Codman, Medina, Penumbra. Istvan Szikora—RELATED: Consulting Fee or Honorarium: Sequent Medical, Comments: clinical trial fee; Support for Travel to Meetings for the Study or Other Purposes: Sequent Medical*; Other: Sequent Medical, Comments: clinical trial fee*; UNRELATED: Consultancy: Stryker, Codman, Medtronic. Xavier Barreau—RELATED: Consulting Fee or Honorarium: Sequent; Support for Travel to Meetings for the Study or Other Purposes: Sequent; UNRELATED: Consultancy: Stryker. *Money paid to the institution.

\section{REFERENCES}

1. Cognard C, Pierot L, Anxionnat R, et al; Clarity Study Group. Results of embolization used as the first treatment choice in a consecutive nonselected population of ruptured aneurysms: clinical results of the Clarity GDC study. Neurosurgery 2011;69:837-41; discussion 842 CrossRef Medline

2. Pierot L, Spelle L, Vitry F. ATENA: the first prospective, multicentric evaluation of the endovascular treatment of unruptured intracranial aneurysms. J Neuroradiol 2008;35:67-70. Erratum in J Neuroradiol 2008;35:252 CrossRef Medline

3. Pierot L, Cognard C, Spelle L, et al. Safety and efficacy of balloon remodeling technique during endovascular treatment of intracranial aneurysms: critical review of the literature. AJNR Am J Neuroradiol 2012;33:12-15 CrossRef Medline

4. Pierot L, Spelle L, Leclerc X, et al. Endovascular treatment of unruptured intracranial aneurysms: comparison of safety of remodeling technique and standard treatment with coils. Radiology 2009;251: 846-55 CrossRef Medline

5. Pierot L, Cognard C, Anxionnat R, et al; CLARITY Investigators. Remodeling technique for endovascular treatment of ruptured intracranial aneurysms had a higher rate of adequate postoperative occlusion than did conventional coil embolization with comparable safety. Radiology 2011;258:546-53 CrossRef Medline

6. Shapiro M, Becske T, Sahlein, et al. Stent-supported aneurysm coiling: a literature survey of treatment and follow-up. AJNR Am J Neuroradiol 2012;33: 159-63 CrossRef Medline

7. Berge J, Biondi A, Machi P, et al. Flow-diverter Silk stent for the treatment of intracranial aneurysms: 1-year follow-up in a multicenter study. AJNR Am J Neuroradiol 2012;33:1150-55 CrossRef Medline

8. Pierot L, Wakhloo AK. Endovascular treatment of intracranial aneurysms: current status. Stroke 2013;44:2046-54 CrossRef Medline
9. Pierot L, Liebig T, Sychra V, et al. Intrasaccular flow-disruption treatment of intracranial aneurysms: preliminary results of a multicenter clinical study. AJNR Am J Neuroradiol 2012;33:1232-38 CrossRef Medline

10. Pierot L, Klisch J, Cognard C, et al. Endovascular WEB flow disruption in middle cerebral artery aneurysms: preliminary feasibility, clinical, and anatomical results in a multicenter study. Neurosurgery 2013;73:27-34; discussion 34-35 CrossRef Medline

11. Papagiannaki C, Spelle L, Januel AC, et al. WEB intrasaccular flow disruptor-prospective, multicenter experience in 83 patients with 85 aneurysms. AJNR Am J Neuroradiol 2014;35:2006-11 CrossRef Medline

12. Lubicz B, Klisch J, Gauvrit JY, et al WEB-DL endovascular treatment of wide-neck bifurcation aneurysms: short- and midterm results in a European study. AJNR Am J Neuroradiol 2014;35:432-38 CrossRef Medline

13. Pierot L, Klisch J, Liebig T, et al. WEB-DL endovascular treatment of wide-neck bifurcation aneurysms: long-term results in a European series. AJNR Am J Neuroradiol 2015;36:2314-19 CrossRef Medline

14. Pierot L, Biondi A, Narata AP, et al. Should indications for WEB aneurysm treatment be enlarged? Report of a series of 20 patients with aneurysms in "atypical" locations for WEB treatment. J Neuroradiol 2017 Mar 2. [Epub ahead of print] CrossRef Medline

15. Pierot L, Moret J, Turjman F, et al. WEB treatment of intracranial aneurysms: feasibility, complications, and 1-month safety results with WEB-DL and WEB-SL/SLS in the French Observatory. AJNR Am J Neuroradiol 2015;36:922-27 CrossRef Medline

16. Pierot L, Moret J, Turjman F, et al. WEB treatment of intracranial aneurysms: clinical and anatomical results in the French Observatory. AJNR Am J Neuroradiol 2016;37:655-59 CrossRef Medline

17. Pierot L, Costalat V, Moret J, et al. Safety and efficacy of aneurysm treatment with WEB: results of WEBCAST study. J Neurosurg 2016; 124:1250-56 CrossRef Medline

18. Pierot L, Spelle L, Molyneux A, et al. Clinical and anatomical follow-up in patients with aneurysms treated with WEB device: 1-year follow-up report in the cumulated population of 2 prospective, multicenter series (WEBCAST, French Observatory). Neurosurgery 2016;78:133-41 CrossRef Medline

19. Muskens IS, Senders JT, Dasenbrock HH, et al. The Woven Endobridge device for treatment of intracranial aneurysms: a systematic review. World Neurosurg 2017;98:809-817.e1 CrossRef Medline

20. Asnafi S, Rouchaud A, Pierot L, et al. Efficacy and safety of the Woven EndoBridge (WEB) device for the treatment of intracranial aneurysms: a systematic review and meta-analysis. AJNR Am J Neuroradiol 2016;37:2287-92 CrossRef Medline

21. Van Rooij W, Peluso JP, Bechan RS, et al. WEB treatment of ruptured intracranial aneurysms. AJNR Am J Neuroradiol 2016;37: 1679-83 CrossRef Medline

22. Herbreteau D, Bibi R, Narata AP, et al. Are anatomical results influenced by WEB shape modification? Analysis in a prospective, single-center series of 39 patients with aneurysms treated with WEB. AJNR Am J Neuroradiol 2016;37:2280-2286 CrossRef Medline

23. Kotowski M, Naggara O, Darsaut TE, et al. Safety and occlusion rates of surgical treatment of unruptured intracranial aneurysms: a systematic review and meta-analysis of the literature from 1990 to 2011. J Neurol Neurosurg Psychiatry 2013;84:42-48 CrossRef Medline

24. Cognard C, Januel AC. Remnants and recurrences after the use of the WEB intrasaccular device in large-neck bifurcation aneurysms. Neurosurgery 2015;76:522-30; discussion 530 CrossRef Medline

25. Pierot L. Letter: WEB aneurysm treatment: stability and "compression.” Neurosurgery 2015;77:E666-67 CrossRef Medline

26. Timsit C, Soize S, Benaissa A, et al. Contrast-enhanced and time-offlight MRA at 3T compared with DSA for the follow-up of intracranial aneurysms treated with the WEB device. AJNR Am J Neuroradiol 2016;37:1684-89 CrossRef Medline 